\title{
Review
}

\section{Antioxidant Activity of Leaves and Fruits of Iranian Conifers}

\author{
S. A. Emami ${ }^{1}$, J. Asili ${ }^{1}$, Z. Mohagheghi ${ }^{1}$ and M. K. Hassanzadeh ${ }^{2}$ \\ ${ }^{1}$ Department of Pharmacognosy, School of Pharmacy, Biotechnology Research Center and ${ }^{2}$ Department of \\ Medicinal Chemistry, School of Pharmacy, Pharmaceutical Sciences Research Center, Mashhad University of \\ Medical Sciences, Mashhad, 91775-1365, Iran
}

\begin{abstract}
Cupressus semipervirens var. horizontalis, Cupressus semipervirens var. semipervirens, Cupressus semipervirens cv. Cereifeormis, Juniperus communis subsp. hemisphaerica, Juniperus excelsa subsp. excelsa, Juniperus excelsa subsp. polycarpos, Juniperus foetidissima, Juniperus oblonga, Juniperus sabina, Platycladus orientalis and Taxus baccata are Iranian conifers. The antioxidant activity of leaves and fruits of these 11 different taxons were evaluated. The leaves of both male and female, and fruits of these plants were collected from different areas of the country. Methanol extract of leaves and fruits of these taxons were prepared. Antioxidant activity of each extracts was measured using two different tests of the ferric thiocyanate method and thiobarbituric acid. Results indicated that the methanol extracts of leaves, of male and female, and fruits of all these species (27 samples) possessed antioxidant activity when tested with both methods. The antioxidant activity was then compared with those of $\alpha$-tocopherol (a natural antioxidant) and butylated hydroxytoluene (a synthetic antioxidant). Methanol extract of fruits of $C$. semipervirens $\mathrm{cv}$. Cereifeormis showed the highest antioxidant activity while the methanol extract of leaves of $C$. semipervirens var. semipervirens possessed the lowest antioxidant activity. However, our finding showed that most of the tested extracts were showing strong antioxidant activity even higher than $\alpha$-tocopherol.
\end{abstract}

Keywords: antioxidative activity - conifers, Cupressus - ferric thiocyanate test - Juniperus medicinal plant - Platycladus orientalis - radical scavenging - thiobarbituric acid test

\section{Introduction}

Lipids containing polyunsaturated fatty acids are readily oxidized by molecular oxygen, and such oxidation proceeds by a free radical chain mechanism (1). Lipid peroxidation can lead to aging, coronary heart disease, stroke, diabetes mellitus, rheumatic disease, liver disorders, multiple sclerosis, Parkinson's disease, autoimmune disease, Alzheimer's and carcinogenesis $(2,3)$. An increasing number of investigations have been carried out to find antioxidative drugs, which not only prolong the shelf life of food products but also participate as radical scavengers in living organisms.

For reprints and all correspondence: Prof. Mohammad HassanzadehKhayyat, School of Pharmacy, Mashhad University of Medical Sciences, Mashhad 91775-1365, Iran. Tel: (0511) 8823255-65; Fax: (0511) 8823251; E-mail: hassanzadeh_mk@yahoo.com
As with other synthetic food additives, commercial antioxidants have been criticized, mainly due to possible toxic effects. Therefore, there is an increasing interest in the antioxidative activity of natural compounds $(4,5)$. They can be an alternative to the use of synthetic compounds in food and pharmaceutical technology or serve as lead compounds for the development of new drugs with the prospect of improving the treatment of various disorders.

Iranian conifers consist of two families: Cupressaceae and Taxaceae. Cupressaceae consist of one species of Cupressus $[C$. semipervirens $\mathrm{L}$. with two varieties: C. semipervirens $\mathrm{L}$. var. horizontalis (Mill.) Aiton and C. semipervirens $\mathrm{L}$. var. semipervirens with a cultivar namely $C$. semipervirens L. cv. Cereifeormis], one species of Platycladus (P. orientalis Franco) and five species of

This is an Open Access article distributed under the terms of the Creative Commons Attribution Non-Commercial License (http://creativecommons.org/ licenses/by-nc/2.0/uk/) which permits unrestricted non-commercial use, distribution, and reproduction in any medium, provided the original work is properly cited. 
Junniperus [J. communis L. subsp. hemisphaerica (Presl) Nyman, J. oblonga M. B., J. sabina L., J. foetidissima Willd. and $J$. excelsa M. B. with two subspecies namely $J$. excelsa M. B. subsp. excelsa and J. excelsa M. B. subsp. polycarpos (K. Koch) Takhtajan]. The Taxaceae consist of only one species of Taxus (T. baccata L.). $C$. semipervirens, $P$. orientalis and J. excelsa M. B. subsp. excelsa are monoecious and others are diecious (6-11).

Iranian conifers are evergreen and aromatic plants are widely spread and grow in different parts of many countries including Iran. Each of them has its own Persian name $(6,8-11)$. Most of these trees are medicinal plants and seeds, dried leaves and fruits are used to treat various diseases like bronchitis, common cold, nose bleeds, hypertension, inflammation and gout, and used as expectorant, contraceptive, diuretics, for rheumatic symptoms, to regulate menstruation and to relieve menstrual pain (12-17). There are some reports on phytochemical and biological studies of some of these taxons as well as other related species (18-21).

There are a few reports about the antioxidant activity of conifers. The antioxidant activity of methanol extract of $J$. chinensis heartwood was determined by DPPH method (22). This plant revealed strong antioxidant activity. In another study, the in vitro antioxidant activity of $J$. communis fruit extracts were evaluated using different antioxidant assay. The results revealed that both the water and ethanol extracts exhibited strong total antioxidant activity (23). The antioxidant and radical scavenging properties of $C$. semipervirence (Cupressaceae) and $J$. procera essential oils were also tested by different methods $(24,25)$.

There are no previous reports concerning antioxidant properties of the extracts of Iranian conifers. Therefore, this study evaluated the antioxidant properties of the methanol extracts of fruits and leaves of both male and female Iranian conifers.

\section{Materials and Methods}

\section{Plant Material}

Plant specimens were collected from different parts of the country (Fig. 1) as follows:

(1) C. semipervirens L. var. horizontalis (Mill.) Aiton [syn. C. horizontalis Mill.] from Sorkesh, Aliabad Katool, Golestan province, height 950m (October 2, 2002). Its Persian name is 'Zarbin'.

(2) C. semipervirens L. var. semipervirens [syn. C. Pyramidalis Targ.-Tozz] from Ecological Garden of Nowshar, Mazandaran province, height $23 \mathrm{~m}$ (October 5, 2002). Its Persian name is 'Sarve Shirazi'.

(3) C. semipervirens L. cv. Cereifeormis from campus of Ferdowsi University, Mashhad, Khorasan Razavi

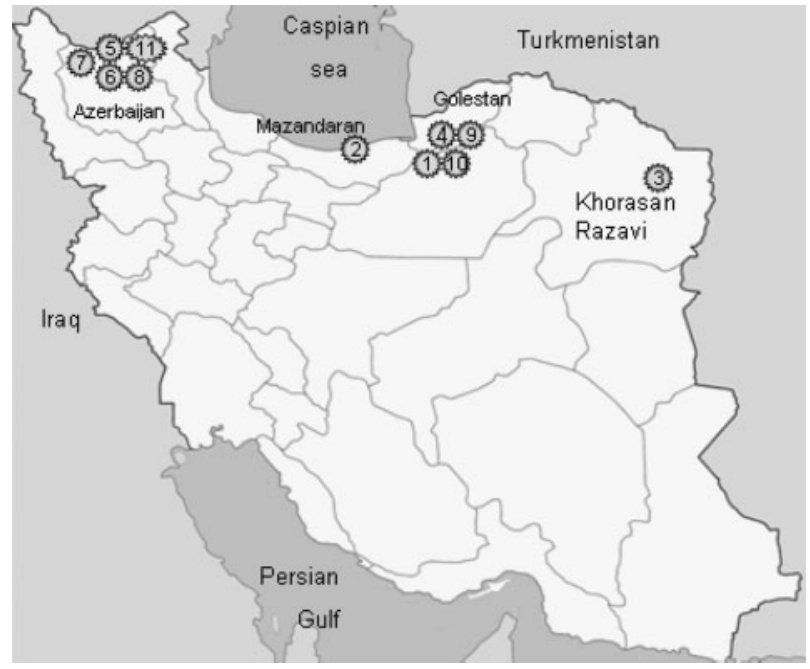

Figure 1. Locations of collected Iranian conifers (numbers as referred in text).

province, height 920m (March 3, 2003). Its Persian name is 'Sarve naz'.

(4) J. communis L. subsp. hemisphaerica (Presl) Nyman [syn. J. hemisphaerica Presl] from an area between Damalo and Cephali, Golestan province, height $2063 \mathrm{~m}$ (October 4, 2002). Its Persian names are 'Lambir' and 'Piru'.

(5) $J$. excelsa M. B. subsp. excelsa from Kelisa Kharabeh, margin of Aras river, East Azarbayejan province, height 1400-1600 m (November 30, 2002). Its Persian name is 'Arduij'.

(6) J. excelsa M. B. subsp. polycarpos (K. Koch) Takhtajan [syn. J. polycarpos K. Koch] from Chopoughlou Darahsi, East Azarbayejan province, height $1593 \mathrm{~m}$ (September 21, 2002). Its Persian name is 'Ors'.

(7) J. oblonga M. B. from an area between Makidi and Vainagh, Arasbaran, East Azarbayejan province, height $1500 \mathrm{~m}$ (July 6, 2002). Its Persian name is 'Chataneh'.

(8) J. foetidissima Willd. from an area between Makidi and Vainagh, Arasbaran, East Azarbaijan province, height of $1400 \mathrm{~m}$ (September 23, 2002). Its Persian name is 'Ardush'.

(9) J. sabina L. from Sourkesh, Aliabad Katool, Golestan province, height $2050 \mathrm{~m}$ (October 3, 2002). Its Persian name is 'Maymarz'.

(10) P. orientalis from Sourkesh, Aliabad Katool, Golestan province, height $851 \mathrm{~m}$ (October 2, 2002). Its Persian names are 'Sarve Khomrehi' and 'Nush'.

(11) T. baccata from Armaniolan, Arasbaran, East Azarbayejan province, height $1175 \mathrm{~m}$ (September 23, 2002). Its Persian name is 'Sorkhdar'.

Dr M. Assadi, Research Institute of Forest and Rangelands, Ministry of Jahad Keshavarzi, Iran, was 
identified these plants. Voucher specimens of the taxons have been deposited in the Herbarium of National Botanical Garden of Iran. The collected materials were stored at $-20^{\circ} \mathrm{C}$ in order to avoid unfavorable changes in the chemical components (26).

\section{Extraction of the Samples}

Individual fresh leaves of male and female of each of the dioecious plants and fresh leaves of monoecious of each taxon (100 g fresh wt.) as well as their fruits (100 g fresh wt.) were cut to small pieces and then ground by a blinder. Each sample was macerated in pure methanol for $24 \mathrm{~h}$. The samples were then extracted using a percolator. The extracted solutions ( 27 samples) were concentrated at $50^{\circ} \mathrm{C}$ to dryness under reduced pressure. The methanol extracts of leaves and fruits of each taxon were evaluated for their antioxidant activity.

\section{Isolation of Volatile Oils}

The volatile oils of fresh leaves and fruits of male and female of each taxon ( $200 \mathrm{~g}$ fresh wt.) were isolated by wet steam distillation for $4 \mathrm{~h}$ (27). The oil samples were dried over anhydrous sodium sulfate. The yield percentages of the essential oils were expressed in $\mathrm{ml} / 100 \mathrm{~g}$ of fresh plant materials.

\section{Isolation and Quantification of Non-volatile Components}

The fruits and leaves of each plant $(500 \mathrm{~g})$ were dried at $50^{\circ} \mathrm{C}$ and then powdered separately. Each powder was defatted with petroleum ether (bp $40-60^{\circ} \mathrm{C}$ ) using Soxhlet apparatus $(6 \mathrm{~h})$. The chemical components of defatted powders were extracted by maceration with methanol (four times). The methanol extracts were concentrated at reduced pressure and the presence of alkaloids (28), flavonoids (29), saponins (30) and tannins (31) were determined.

\section{Antioxidant Assays}

Several reports have evaluated the antioxidant activity of various essential oils and extracts of different plants $(1,4,32)$. In this study, the methanol extracts of leaves, of male and female, and fruits of eleven different taxons of Iranian conifers (27 samples) were evaluated for their antioxidant activity (final concentration $0.02 \% \mathrm{w} / \mathrm{v}$ ). Ferric thiocyanate (FTC) and thiobarbituric acid (TBA) methods were used to evaluate antioxidant activity (33). Vitamin E and butylated hydroxytoluene (BHT) $(0.02 \%)$ were used as standards in both methods. One sample without antioxidant activity was also used as control.

In these experiments, for inhibition of linoleic acid peroxidation, the reaction mixture was composed of linoleic acid in ethanol, the sample solution, $0.05 \mathrm{~mol} / 1$ phosphate buffer ( $\mathrm{pH}$ 7.0) and water. Following incubation, the degree of oxidation was measured according to FTC and TBA methods. To calculate the percentage of antioxidant activity, after reading the absorbance of samples at $500 \mathrm{~nm}$ for FTC method and at $532 \mathrm{~nm}$ for TBA method, the percentage of activity was calculated according to the following equation:

$$
\frac{A I(\%)=100 \times\left(A_{0}-A\right)}{A_{0}}
$$

where $A_{0}$ is the absorbance of the control reaction (reaction, containing no test compound) and $A$ is the absorbance of the test compound. The values obtained for the control samples were taken for $100 \%$ lipid peroxidation.

\section{Statistical Analysis}

All experiments were repeated three times and an average used for calculating the antioxidants activity of each sample. The antioxidant activity of the extracts and positive controls were compared by ANOVA one-way test, $(P \leq 0.05)$, using SPSS program.

\section{Results}

\section{Antioxidant Assays}

The leaves, of male and female, and fruits of all 11 different taxons of Iranian conifers (27 samples) evaluated for their antioxidant activity showed strong antioxidant activity by both FTC and TBA methods (Figs 2 and 3 ). The activity of BHT was $\sim 100 \%$ (the average absorbance of the BHT in both FTC and TBA methods was 0.002 in comparison with the control sample absorbances which were 0.868 and 0.635 ). Using FTC method, antioxidant activity of the extracts was $\sim 78-99 \%$ and $\sim 60-99 \%$ by the TBA method

\section{Volatile Oils and Non-volatile Components}

The amount of non-volatile components (from defatted methanol extracts) of the fruits and leaves as well as the yield percentages of the essential oils are shown in Table 1.

\section{Discussion}

There is a strong need for effective antioxidants from natural sources as alternatives to synthetic food additives in order to prevent deterioration of foods, drugs and cosmetics. The extracts and essential oils of many plants have been investigated for their antioxidant activity $(1,4,32)$. In this study, the antioxidant properties of the methanol extracts of leaves, of male and female, and fruits of 11 different taxons of Iranian conifers; C. semipervirens var. horizontalis, $C$. semipervirens var. semipervirens, C. semipervirens cv. Cereifeormis, 


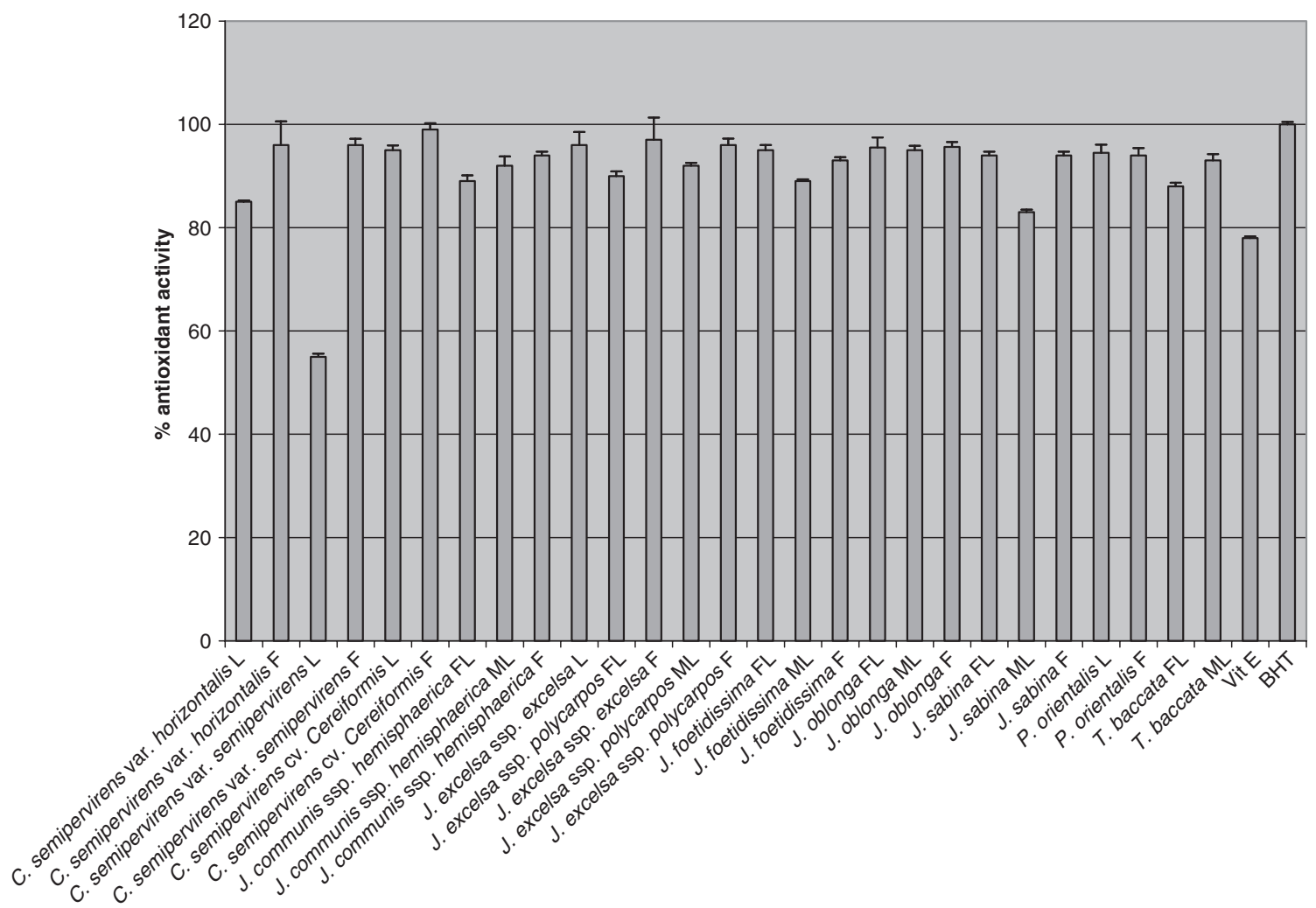

Figure 2. Antioxidant activity ( $\% \pm \mathrm{SD})$ of methanol extracts of leaves of male (ML) and female (FL) and fruits (F) of 11 different taxons of Iranian conifers (final concentration $0.02 \% \mathrm{w} / \mathrm{v}$ ) measured using FTC method $(n=3)$.

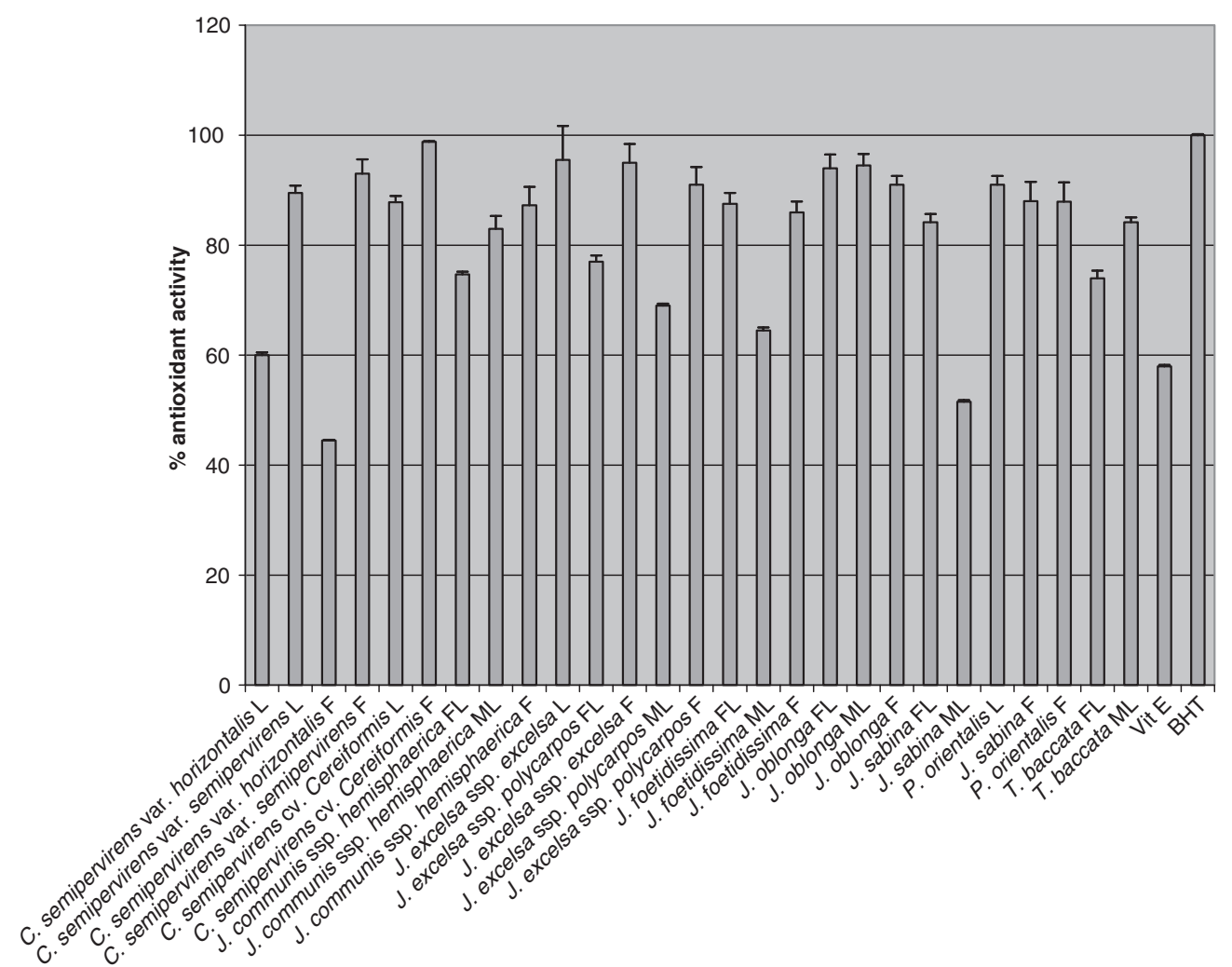

Figure 3. Antioxidant activity $(\% \pm \mathrm{SD})$ of methanol extracts of leaves of male $(\mathrm{ML})$ and female (FL) and fruits (F) of 11 different taxons of Iranian conifers (final concentration $0.02 \% \mathrm{w} / \mathrm{v})$ measured using TBA method $(n=3)$. 
Table 1. Major components of fruits and leaves of Iranian conifers

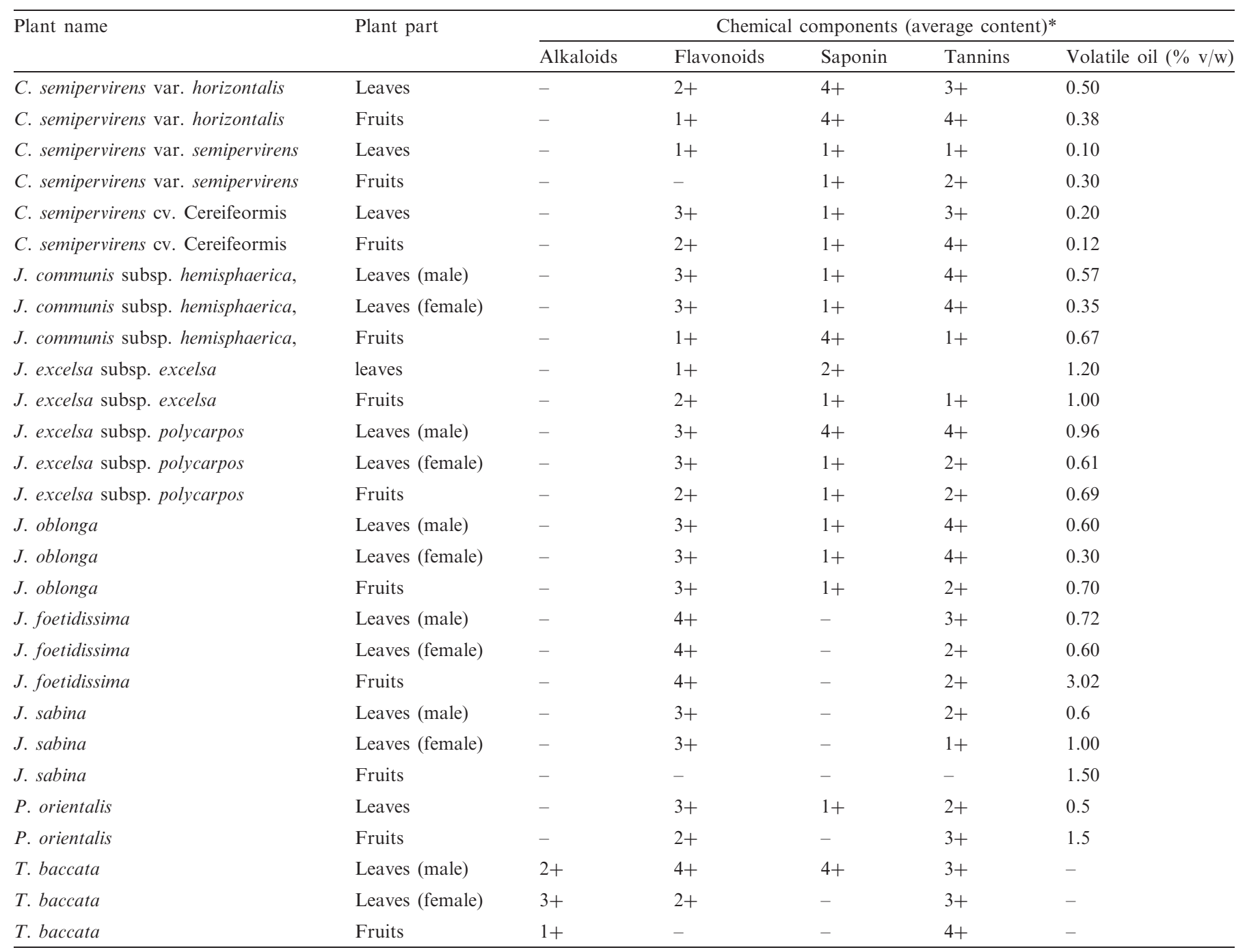

*Average content was rated from - to $4+;+$, slightly positive; ++ , moderately positive; +++ , strongly positive; ++++ , very strongly positive; - , not detected.

J. communis subsp. hemisphaerica, J. excelsa subsp. excelsa, J. excelsa subsp. polycarpos, J. oblonga, J. foetidissima, J. sabina, P. orientalis and Taxus baccata, were examined.

The inhibitions of activities against lipid peroxidation in linoleic acid were evaluated by measuring the concentration of the TBA-reactive substances and FTC.

The FTC method measures the amount of peroxide produced during the initial stage of lipid oxidation. Subsequently, at a later stage of lipid oxidation, peroxide decomposes to form carbonyl compounds that are measured by using the TBA method. The entire methanol extracts possessed strong antioxidant activity (low absorbance values) by both the FTC and TBA methods. The antioxidant activity was then compared with those of $\alpha$-tocopherol (a natural antioxidant) and BHT (a synthetic antioxidant). Different extracts obtained from different parts of the plants exhibited strong antioxidant activity within the range of $78-99 \%$ by the FTC method (except for leaves of $C$. semipervirens var. semipervirens which was $55 \%$ ) (Fig. 2). Using the TBA method, all extracts also showed strong antioxidant activity within the range of 60-99\% (except for leaves of $C$. semipervirens var. semipervirens and male leaves of $J$. sabina which were 44.5 and $51.5 \%$, respectively), (Fig. 3). The pattern of activity was very similar for both methods. C. semipervirens cv. Cereifeormis fruits' methanol extract exhibited the highest antioxidant activity (quite higher than $\alpha$-tocopherol) in both methods. Among the extracts examined, the leaves of $C$. semipervirens var. semipervirens methanol extract possessed the lowest antioxidant activity. 
This may be partially due to the low amounts of flavonoids and tannins in the leaves of $C$. semipervirens var. semipervirens.

A few studies on antioxidant activity of these plants' extracts also showed the same results. The methanol extracts of $J$. chinensis heartwood revealed the strong antioxidant activity (22). Results of a study of antioxidant activity of $J$. communis fruit extracts in in-vitro support our findings (23).

Antioxidant activity and its strength in each plant depends on the existence of various compounds in that plant. Antioxidative and radical scavenging activities of flavonoids are well studied (34). Some of phenolic compounds (anthocyanidin, catechines, flavones, flavonols and isoflavones), tannins (ellagic acid, gallic acid), phenyl isopropanoids (caffeic acid, coumaric acids, ferulic acid), lignans, catchol and many others are antioxidants (35). Several different essential oils obtained from various plants and their components have also been studied for their antioxidant activities (36). Figures 1 and 2 indicate different extracts obtained from the leaves, of male and female, and fruits of all 11 different taxons showed different strength of antioxidant activity by both FTC and TBA methods. The methanol extract of the tested plants contains various non-volatile and volatile compounds (Table 1). As it can be seen from Table 1, the amounts of non-volatile compounds in leaves and fruits of them vary significantly. In all them (except for T. baccata), the amount of alkaloids was not detectable while the amounts of flavonoids, saponins and tannins were very different. Variation in the amounts of various non-volatile and volatile compounds in different tested plant can be one of the reasons causing differences in antioxidant activity of the extracts obtained from different plants as well as from different parts of each plant.

Finally, while further investigation is necessary to separate the component of each extracted sample and then evaluate the antioxidants activity of each component using several different methods, at this stage, methanol extracts of these plants can be considered as a strong antioxidant agent.

\section{References}

1. Aruoma OI. Free radicals, oxidative stress, and antioxidants in human health and disease. J Am Oil Chem Soc 1998;75:199-212.

2. Lin $\mathrm{CC}, \mathrm{Wu} \mathrm{SJ}$, Chang $\mathrm{CH}, \mathrm{Ng} \mathrm{LT}$. Antioxidant activity of Cinnamomum cassia. Phytother Res 2003;17:726-30.

3. Loliger J. Free Radicals and Food Additives. London: Taylor and Francis, 1991, 121-50.

4. Amakura Y, Umino Y, Tsuji S, Ito H, Hatano T, Yoshida T, et al. Constituents and their antioxidative effects in eucalyptus leaf extract used as a natural food additive. Food Chem 2002;77:47-56.

5. Orhan I, Aydin A, Colkesen A, Isimer AI. Free scavenging activities of some edible fruit seeds. Pharmaceut Biol 2003;41:163-5.

6. Sabeti H. Forests, Trees and Shrubs of Iran. Tehran, Iran: Ministry of Information and Tourism Press, 1976, 418-9.
7. Riedl H. Cupressaceae. In: Rechinger KH (ed.). Flora Iranica: No 50. Graz, Austria: Akademische Druck- u. Verlagsanstalt, 1968, $1-10$.

8. Parsa A. Flore de I'Iran. Tome 5, Teheran, Iran: Publication du Minstere de I'Education, Museum d'Histoire Naturelle, 1949, $460-93$.

9. Assadi M. Taxaceae. In: Assadi M, Khatamsaz M, Maassomi AA, Mozafarian V (eds). Flora of Iran: No. 20. Tehran, Iran: Research Institute of Forest and Rangelands, 1998, 6.

10. Assadi M. Cupressaceae. In: Assadi M, Khatamsaz M, Maassomi AA, Mozafarian V (eds). Flora of Iran: No. 21. Tehran, Iran: Research Institute of Forest and Rangelands, 1998, 8-28.

11. Mozafarian V. A Dictionary of Iranian Plant Names, Vol. 169. Tehran, Iran: Farhang Moasser Publication, 2003, 297-8.

12. Agrawal OP, Bharadwaj S, Mathur R. Antifertility effects of fruits of Juniperus Communis. Planta Med Suppl 1980;40:98-101.

13. Anonymous. PDR for Herbal Medicines, 3rd edn. Montvale: Thomson PDR, 2004, 249477-81, 610-1, 706-7, 907-8.

14. De Medina FS, Gamez MJ, Jimenez I, Osnua JI, Zarzuelo A. Hypoglycemic activity of juniper "berries". Planta Medica 1994;60:197-200.

15. Fournier G, Pages W, Fournier C, Callen G. Contrabution a la etude sur les huilles essentielle des divers éspeces de Juniperus. $J$ de pharmacie de Belgique 1990;45:293-8.

16. Prakash AO. Biological evaluation of some medicinal plant extracts for contraceptive efficacy. Contracept Delivery Syst 1984:53:9-10

17. Yesilada E, Honda G, Sezik E, Tabata M, Fujita T, Tanaka T, et al. Traditional medicine in Turkey, V. Folk medicine in the inner Taurus Mountains. J Ethnopharmacol 1995;46:133-52.

18. Milos M, Randonic A. Essential oil and glycosidically bound volatile compounds from Croatian Cupressus semipervirens L. Acta Pharmaceutica 1996;49:309-14.

19. Mikaia G, Turabelidze D, Vulfson N, Kemertelidze E. Diterpene labden diole from shoots of Juniperus oblonga. Bull Georgian Acad Sci 1996;153:391-3.

20. Pisarev DI, Denisenko ON, Pyatigorsk G. The composition of essential oils in juniper (Juniperus oblonga) needles and fruits. Farm Akad Russia Farmatsiya 2005;1:12-4.

21. Naser B, Bodine C, Tegtmeir M, Lindequist U. Thuja occidentalis (Arbor vitae): a review of its pharmaceutical, pharmacological and clinical properties. Evid Based Alternat Med Complement 2005;2:69-78.

22. Jong PL, Young CS, Jin WK, Chung HK, Jae SE, Kang HL, et al. Free radical scavengers from the heartwood of Juniperus chinensis. Arch Pharmacal Res 2002;25:449-52.

23. Elmastas M, Gulcin I, Beydemir S, Kufrevioglu OI, AboulEnein HY. A study on the in vitro antioxidant activity of Juniper (Juniperus communis L.) fruit extracts. Anal Let 2006;39:47-65.

24. Sacchetti G, Maietti S, Muzzoli M, Scaglianti M, Manfredini S, Radice M, et al. Comparative evaluation of 11 essential oils of different origin as functional antioxidants, antiradicals and antimicrobials in food. Food Chem 2005;91:621-32.

25. Burits M, Asres K, Bucar F. The antioxidant activity of the essential oils of Artemisia afra, Artemisia abyssinica and Juniperus procera. Phytother Res 2001;15:103-8.

26. Adams RP, Zanoni TA, Hogge L. The volatile leaf oils of Juniperus flaccida var. flaccida and var. poblana. J Nat Prod 1984;47:1064-5.

27. Kirk-Othmer. Encyclopedia of Chemical Technology, Vol. 16. New York: Wiley, 1978, 313.

28. Evans WC. Trease and Evans Pharmacognosy, 15th edn. London: W.B. Saunders, 2002, 138-9, 221-2, 336-7.

29. Markham RK. Techniques of Flavonoids Identification. London: Academic Press, 1982, 45.

30. Hostettmann K, Martson A. Saponins. Cambridge: University Press, 1995, 233.

31. Bruneton J. Pharmacognosie Phytochimie Plantes medicinales. Paris: TEC \& DOC, 1999, 381-5.

32. Da Silva JMR, Darmon N, Fernandez Y, Mitjavila S. Oxygen free radical scavenger capacity in aqueous models of different procyanidins from grape seeds. J Agric Food Chem 1991;39:1549-52.

33. Mackeen MM, Ali AM, Lajis NH, Kawazu K, Hassan Z, Amran M, et al. Antimicrobial, antioxidant, antitumour-promoting 
and cytotoxic activities of different plant part extracts of Garcinia atroviridis Griff. ex T. Anders. J Ethnopharmacol 2000;72:395-402.

34. Das NP, Ramanathan L. Studies on flavonoids and related compounds as antioxidants in food. In: Ong ASH, Packer L (eds). Lipid-Soluble Antioxidants: Biochemistry and Clinical Applications. Switzerland: Birkhäuser Verlag, 1992, 295-306.
35. Rice-Evans CA, Miller NJ, Paganga G. Structure-antioxidant relationships of flavonoids and phenolic acids. Free radic Biol Med 1996;20:933-56.

36. Ruberto G, Baratta MT. Antioxidant activity of selected essential oil components in two lipid model system. Food Chem 2000;69: $167-74$.

Received May 28, 2006; accepted January 16, 2007 


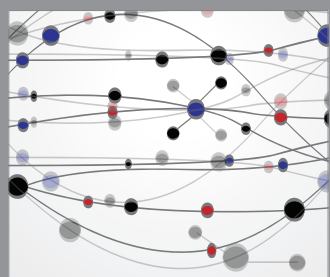

The Scientific World Journal
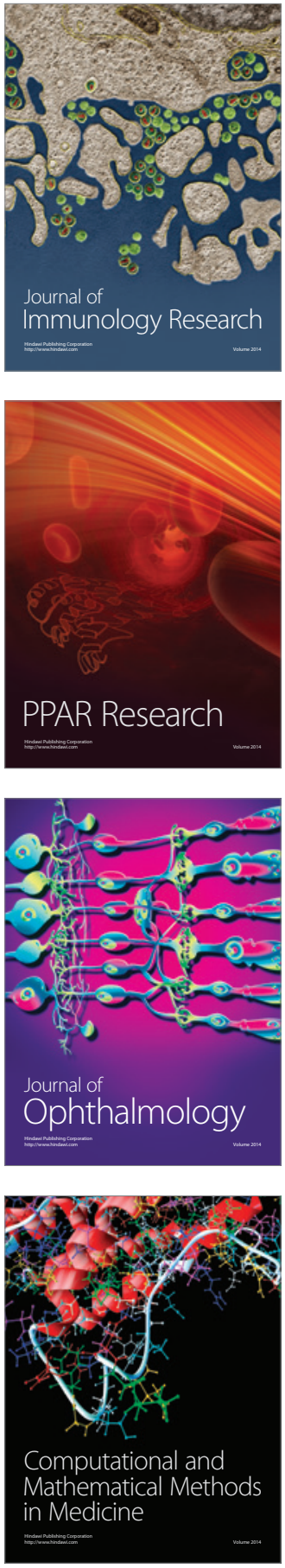

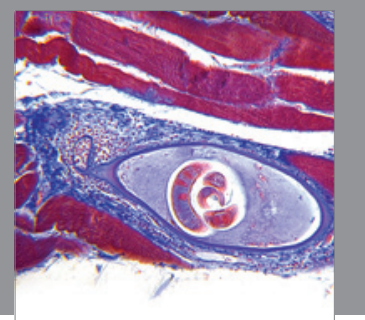

Gastroenterology

Research and Practice
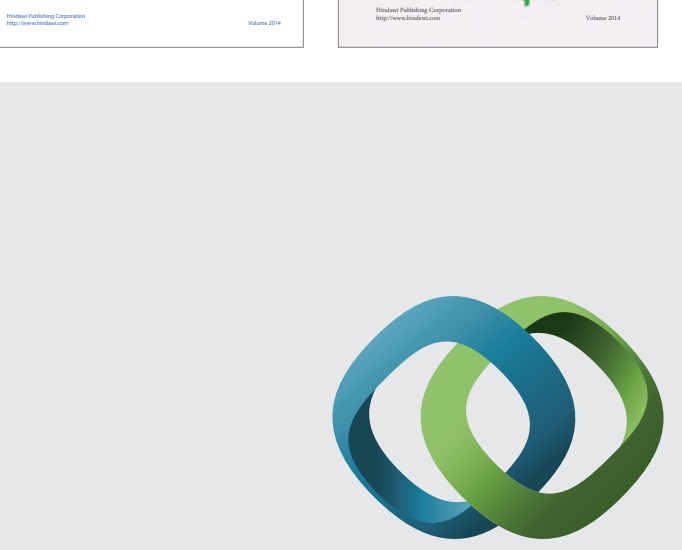

\section{Hindawi}

Submit your manuscripts at

http://www.hindawi.com
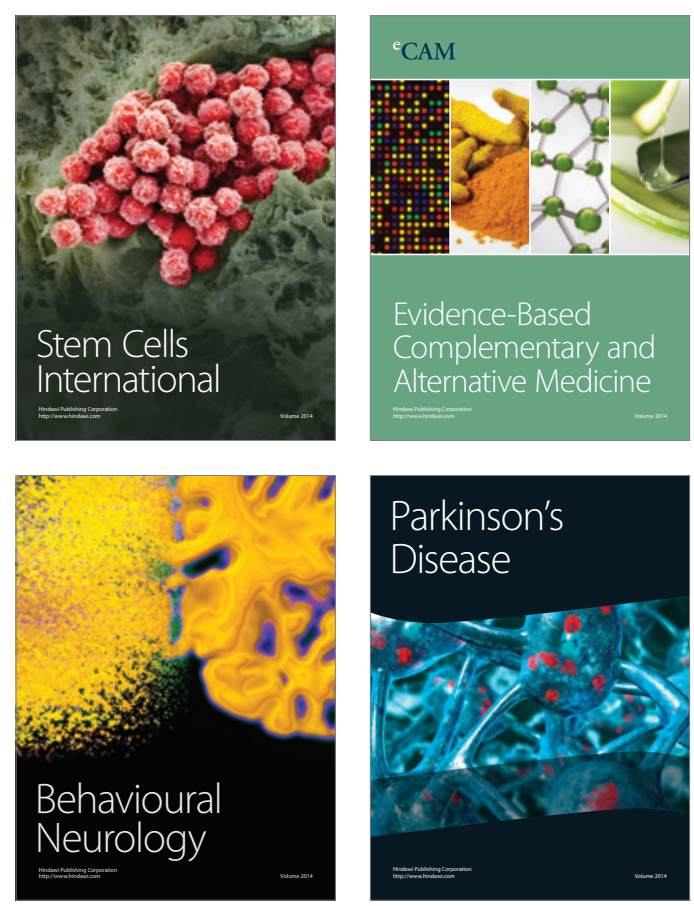

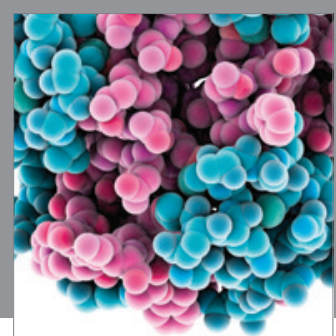

Journal of
Diabetes Research

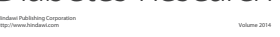

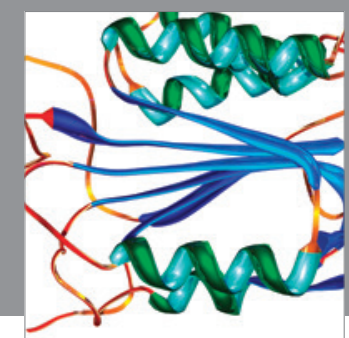

Disease Markers
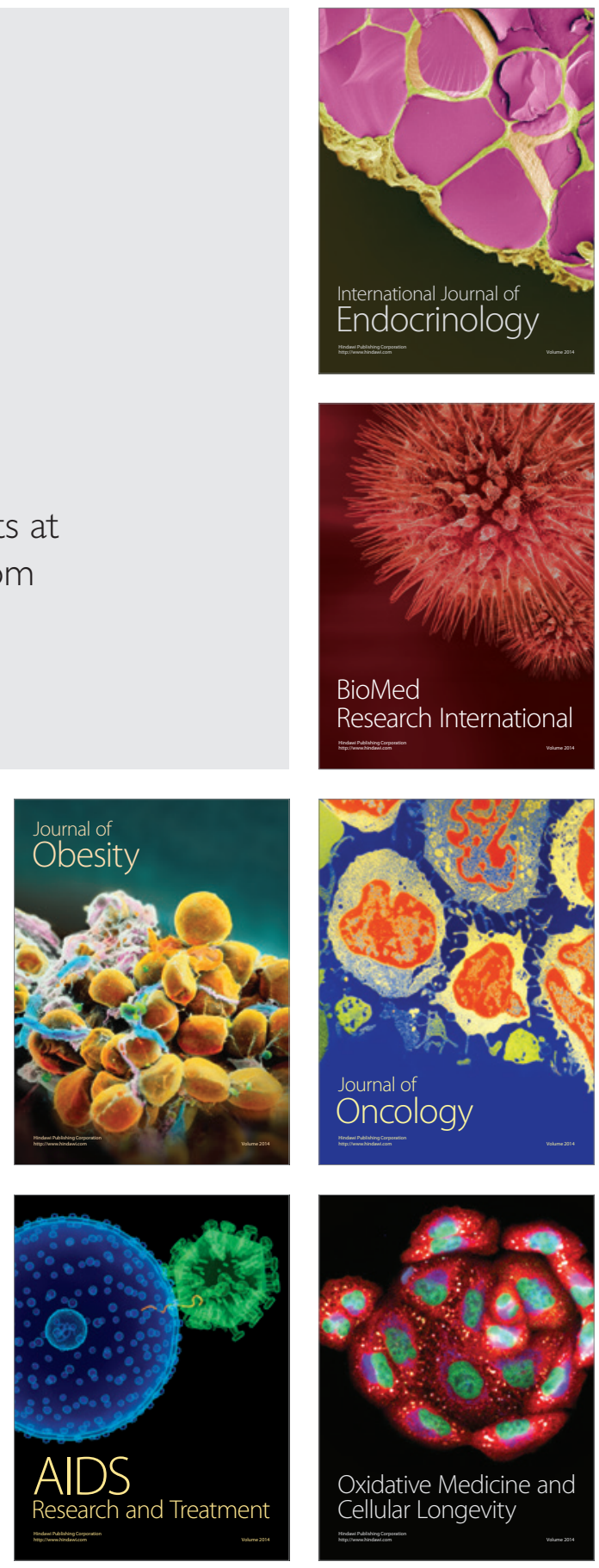